lesions limited to the lateral surfaces of the hemispheres in the region of the angular gyri, we can probably attribute the disturbances of visual space perception to destruction of this portion of the parietal association area. It is interesting that certain observations made thirty years ago by Sir E. Sharpey-Schafer on monkeys from which he removed the angular gyri, can now be interpreted as the result of affection of space perception, similar to that with which my patients suffered.

\section{Nature OF THE Symptoms.}

In attempting to analyse these symptoms and interpret their nature and significance we must consider the physiological factors on which spatial localization by sight and tridimensional vision depend.

The simplest case is localization in a bidimensional plane represented by a hollow sphere, the centre of which would correspond to the pupil. When the eye is focussed on any point on this sphere the concave surface of the retina receives images of all objects that lie on the arc within its field of vision. Then we can recognize the relation in space of any one of these objects to that on which our eyes are directed, and the relation of any other two objects on this arc to one another. This we do by virtue of the local signs of the stimulated retinal points, just as by means if the cutaneous local signs we can ocalize any contact on the surface of our body.

But such local signs can serve us only in relative localization to some central point or to our visual axes; they cannot inform us of the absolute position in space of any object with reference to ourselves, as they take no account of the position of our eyes, of our heads, or even of our whole bodies. This additional information we must. obtain from proprioseptive impressions from the ocular muscles, from our labyrinth, and from the muscles of our bodies; and when by virtue of these we can become aware of our position in space and the direction in which our eyes are looking, we can, by using the retinal local signs, determine the absolute position in space of the object we see in relation to ourselves. Even in this simple case the association of retinal and various proprioceptive afferents is necessary, and the loss of any of these factors may disturb this function. In the cases described here, the afferents from the labyrinths, and from the ocular and other muscles, were unimpaired, and the symptoms must be attributed either to a disturbance of the local sign functions of the retina, or to the failure of the brain to associate and integrate these with other afferent impressions. Many direct observations showed that the retinal local signs were affected.

We have to deal with a more complex condition in considering the perception of distance, as there are several other factors concerned in this. Binocular vision undoubtedly plays a part, and the proprioceptive impressions from the intrinsic and extrinsic ocular muscles that are excited by accommodation and convergence contribute to it when the object is near. The estimation of distance, is also aided by the apparent size of known objects, by their distinctness and light intensity, and by the parallax that is obtained on movement of either our heads or of the objects. There is no evidence that any of these separate factors were disturbed in my cases. The inability to estimate distance must be ascribed to failure to correlate and associate the various afferent impressions on which per. ception of the third dimensions may be based, and to assimilate them with past experiences and thereby supply to consciousness the data on which a correct intellectual judgement can be made.

Loss of stereoscopic vision might be regarded as a natural consequence of inability to appreciate relative distances since, it might be argued, this would make it impossible to discriminate the depths of the different portions of a tridimensional figure. But stereoscopic vision was affected in only one of the eight cases in which the perception of distance was seriously disturbed. The physiological factors on which it depends have been the subject of much discussion; the appreciation of relative distance, difference in light and shade, the parallax and the sense of perspective, all undoubtedly play a part, but it is to the fusion of the non-corresponding images formed in the two eyes and their integration with these other sensory data into a single concept that we mainly owe the appreciation of depth in objects seen. There was no gross disturbance of any of these individual factors in $\mathrm{my}$ cases except the appreciation of relative distance, which the intact faculty of stereoscopic vision in the other cases shows was not sufficient. An affection of the sense of perspective may have contributed, but as this faculty is of intellectual origin and acquired by training and experience, we are ultimately forced to regard loss of stereoscopic vision, too, as the result of a failure to combine and associate the different sensations on which the appropriate intellectual judgements can be made, rather than as due to the loss of any of the physiological factors on which it depends.

1 Holmes: Brit. Journ. of Ophthalmol., 1918, vol. ii, p. 449. Holmes and Horrax: Archiv. of Neurol. and Psychiatr., 1919, vol. i, p. 385.

\section{A CRITICISM OF CERTAIN RECENT CLAIMS TO HAVE DISCOVERED AND CULTIVATED THE FILTER-PASSING VIRUS OF TRENCH FEVER AND OF INFLUENZA.}

\author{
BY
}

\section{J. A. ARKWRIGHT, M.D.}

(From the Lister Institute of Preventive Medicine.)

IN recent papers by Bradford, Bashford and Wilson 128480 , it is clainued (1) that six diseases including trench fever and influenza, which have up to the last twelve months baffled investigators, have been shown conclusively to be caused by organisms which pass filters of such a quality that they hold back ordinary bacteria; (2) that in the case of seven other diseases (thirteen in all) the virus has been cultivated and can be recognized microscopically when stained by suitable methods.

Most of the work has been published only in the form of condensed epitomes, but rather fuller details on which these claims are based have been recorded for two diseases -namely, "epidemic polyneuritis" and influenza.

These papers have attracted considerable attention on account of the extent and importance of the results claimed.

\section{Other Recent Attempts to Cultivate a Filter-passing} Virus of 'Trench Fever or of Influenza.

A good deal of work in recent years has encouraged the view that the viruses of trench fever and influenza are of such a kind that their filtrability may bo ultimately established, and has prepared the way for further researches on the cultivation of filtrable viruses.

1. The American Red Cross Committee on Trench Fever publish ${ }^{2}$ evidence ${ }^{7}$ that the virus of trench fever would in some instances pass through a Chamberland filter " $L$ " with a pressure of $760 \mathrm{~mm}$. of mercury.

2. The War Office Trench Fever Committee in London (1918-19) has made five inoculations of filtrates of emulsions of infected louse excreta into volunteers. The filters used were in one case a Chamberland " $F$," in the others British "Berkefelds." Only one of these experiments was definitely successful, and in this case the filter used was not satisfactory. The results were as follows:

(a) Experiment 153.-20 c.cm. of a 1 per cent. emulsion filtered at a negative pressure of 350 to $400 \mathrm{~mm}$. of mercury through a Chamberiand " $\mathrm{F}$ " filter. Result, negative.

(b) Experiment 187.-10 c.cm. of a 1 per cent. emulsion filtered at a negative pressure of 200 to $300 \mathrm{~mm}$. of mercury through a Berkefeld were injected intravenously. The man had a rise of temperature to $103^{\circ} \mathrm{C}$. and abdominal pain on the eighth day from the inoculation, but no further symptoms suggestive of trench fever.

(c) Experiment 190.-10 c.cm. of a 1 per cent. emulsion filtered at a negative pressure of 300 to $350 \mathrm{~mm}$. of mercury through a Berkefeld were injected intravenously. The result was negative.

The above filters kept back $B$. prodigiosus under conditions like those of the experiments.

(d) Experiment 199.- 35 c.cm. of a Berkefeld filtrate of a 0.5 per cent. emulsion were inoculated subcutaneously. The filtration took place at a negative pressure of 600 to $740 \mathrm{~mm}$ of mercury. The man developed trench fever on the sixt day and had several relapses.

(e) Experiment 200.-49 c.cm. of a Berkefeld filtrate of the same emulsion as that used in the last experiment was inoculated subcutaneously. 'The filtrate was obtained at a 
negative pressure of between 600 and $720 \mathrm{~mm}$. of mercury. The result was negative.

Neither of the filters used in Experiments $(d)$ and $(e)$ completely retained the $B$. prodigiosus of a test emulsion used under the same conditions as the experiments.

It seems, therefore, fair to assume that the virus of trench fever consists of particles of such a size that they are to a large extent, but not necessarily entirely, stopped by a filter which will let through a small proportion of the $B$. prodigiosus in an emulsion at the same pressure and within a period of one or two hours. That is, that probably the size of the individuals in the trench fever virus approximates to that of the smallest members of an emulsion of B. prodignosus.

3. The work of Töpfer, ${ }^{8}$ Munk and Rocha Lima, ${ }^{9}$ Ark wright, Bacot and Duncan, ${ }^{10}$ and others has shown the close association of trench fever virus in the louse with minute bodies (rickettsia) about 0.3 to 0.5 micron in diamet $\mathbf{r}$.

4. Selter (1918), ${ }^{11}$ Nicolle and Lebailly (1918), ${ }^{12}$ Gibson Bowman and Connor (1918), ${ }^{13}{ }^{14} 15$ v. Angerer (1918), ${ }^{16}$ Binder and Prell (1918), ${ }^{17}$ and others have brought forward evidence that they have passed the virus of influenza through filters which liept back bacteria, and that they have reproduced the disease in animals, not only with the filtrate but with cultures made from the filtrate.

5. Again, the work of Flexner and Noguchi $(1913)^{18}$ on a filter-passing organism of poliomyelitis initiated methods of the kind used by Bradford, Bashford and Wilson, and they produced strong evidence in favour of their so-called " globoid bodies" as a cause of this disease.

6. Other work - for example, that of G. B. Foster $(1917)^{19}$ on the culture of the organism of "common colds," and of Noguchi (1913) ${ }^{20}$ on the virus of rabies-has tended to support the conclusion that these "filter-passing "organisms can be cultured in artificial media and recognized micro. scopically in the cultures.

The work on poliomyelitis has not, however, met with universal acceptance as regards the morphology of the micro-organisms, and that on "common cold" is uncon firmed. Noguchi's work on rabies has been strongly con tested by Kraus (1914), ${ }^{21}$ who claimed to have found identical bodies in uninoculated ascitic fluid.

As a member of the War Office 'Trench Fever Committee under the chairmanship of Major-General Sir David Bruce and in collaboration with Bacot and Duncan, the present writer has been working during the last eighteen months on the virus and the mode of transmission of trench fever, and has been engaged in various attempts to obtain cultures of this virus, and to determine the relation of rickettsia to the virus.

He has therefore been led to study in detail the method and results of Bradford, Bashford and Wilson, and to try to confirm their findings. This attempt was at the outset particularly interesting to him, since the forms described by Bradford and Wilson in trench fever were stated to be of approximately the same size as rickettsia bodies.

\section{Writer's Attempts to Cultupe the Viruses of} Trench Fever and Influenza.

Since early in 1918 the present writer has been making numerous attempts to cultivate the virus of trench fever from infected louse excreta and from patients' blood on a variety of media, including modifications of Noguchi's medium for spirochaetes and blood broth incubated aërobically and anaërobically. Since the publication of Bradford, Bashford and Wilson's papers on polyneuritis in the Quarterly Journal of Medicine (October, 1918, and January, 1919), he has also worked with the modification of Noguchi's medium used by Wilson.

Early in 1919 some attempts were made to grow the virus of influenza from filtered and from glycerinated sputum, on account of the publication of the experiments by Gibson, Bowman and Connor (X, 1918).13

Three samples of influenza sputum were used for the culture experiments. The writer has therefore become familiar practically with the macroscopical and microscopical changes in tubes of these media due to various forms of precipitated protein.

Since May, 1919, a considerable number of tubes of the modification of Noguchi's medium used by Wilson have been prepared and incubated at $37^{\circ} \mathrm{C}$. Some of them have been inoculated with trench fever virus, and the remainder have not been inoculated, but have served as controls. A few Noguchi's tubes without agar have also been prepared; horse serum has been used generally, but rabbit serum has also been tried. Four series of tubes have been inoculated with filtered louse excreta and one with glycerinated excreta.

All the tubes have been watched for the appearance of turbidity or the formation of deposit, and samples of the deposit have been removed with pipettes, stained and examined microscopically. Twenty-three such culture tubes were inoculated with an emulsion of louse excreta infected with trench fever virus after filtration through a Berkefeld filter; of these, three (13 per cent.) were con. taminated with bacteria. Twenty-one were inoculated with the blood of a trench ferer patient taken on the serenth day of disease counting from the onset of fever; of these, six were contaminated (28.5 per cent.). of 46 control tubes, 10 proved to be contaminated (21.7 per cent.). Thus out of 90 tubes in all, 19, or about 21 per cent., proved to be contaminated by bacteria after two or three weeks' incubation at $37^{\circ} \mathrm{C}$., or earlier.

Of the 19 tubes containing bacteria, 4 contained a diph. theroid bacillus, 2 streptococci, 3 cocci not in chains, 3 a gas-forming organism, and 7 other less well characterized bacteria.

Of the 10 contaminated control tubes 2 contained diph. theroids, 1 a coccus, 1 a gas-producing sporer, 1 another gas former, and 5 had kinds of bacteria which were not accurately defined.

\section{Macroscopic Appearances of the Culture Tubes.}

The results of observations on the above culture tubes may briefly be given as follows: The writer was unable to distinguish between the culture tubes which had been inoculated and those which had not been inoculated. Great differences existed between tubes of the same age, but, whenever a tube showed a high degree of turbidity or a large amount of deposit, corresponding to that called a free growth in tubes shown by Captain Wilson at the British Medical Association meeting in April, 1919, or figured in the paper on influenza virus by Bradford, Bash. ford and Wilson, in the Quarterly Journal of Medicine, vol. xii, No. 47, plate 16 (opposite p. 206), figure A (3), then the tube in question could be shown to contain bacteria, readily demonstrated in films stained by Giemsa or Gram and fuchsin, and by cultivation on agar and in broth.

Some turbidity of the serum-agar, and a change in the appearance and woolliness in outline of the piece of rabbit kidney and more or less granular deposit on the surface of the agar occurred in all tubes after five to ten days' incubation.

\section{Microscopical Appearances.}

Films of the deposit from the tubes were stained by carbol-methylene blue (Kühne's formula) for one or two hours or by Giemsa (1 drop to 1 c.cm.) for twelve to twenty hours, and examined with a No. 4 eyepiece and a 1/12 oil immersion objective.

The appearances were extremely varied as to the number, size, shape, and degree of staining of the granules seen in the films. - They were so different in samples from different control tubes that a standard of what was to be expected in a "control" was very difficult to establish. In addition the temperature and the rate of drying, thickness of the film, and the method of fixing all made differences in the microscopical appearances. As a rule the films were dried in the incubator at $37^{\circ}$ C., and latterly were fixed in the flame, as this method of fixing was that used by Captain Wilson; previously they had been fixed in alcohol. It is recognized, I suppose, by every one who has worked with stained films from broth cultures of bacteria that the irregular shape and staining of the micro-organisms and of the precipitated protein, etc., make very disconcerting and puzzling pictures: When the culture medium contains serum or blood also, and has been incubated for five days or more, and a deposit has formed, the difficulties are intensified, especially if a weak stain is used.

Remarks on the Methods used by Bradford, Bashford AND WILSON FOR INVESTigation of The Filter-PASSing Viruses, and the Results of their Atiempts at Culture.

In order to prove or adduce reasonably good evidence that a micro-organism is the cause of a given disease, it is not only necessary that the disease should be clinically 
or pathologically clearly defined, but that the microorganism should have such definite characters, cultural, microscopical, etc., that it can be recognized without doubt when met with. It is very necessary, therefore, in the present instance that the claim to be able to differentiate in cultures and films between the various filter-passing organisms described, and between them and bacteria of more usual size, should be very thoroughly established.

Animal Experiments reproducing the Disease and

Recovery of the Virus in a Recognizable Form from the Infected Animals.

Indubitable results from these experiments are only claimed in six diseases, including influenza and trench fever. I have seen none of the animal experiments, and do not propose to discuss them. The War Office Trench Fever Committee has, however, attempted the production of disease in man by inoculating three volunteers with "cultures" obtained by inoculating media of the same kind as that used by Captain Wilson. The results were negative in two cases and not at all characteristic in the third; a rise of temperature to $100^{\circ} \mathrm{F}$. on the nineteenth day being the only symptom produced. This result was, therefore, quite inconclusive.

It must be remembered, moreover, that evidence that the virus increases in vitro, as demonstrated by inocula. tion, is no proof that bodies seen in the cultures are identical with the virus or materies morbi.

1. Filtration.-Although it is stated that the different kinds of virus were filtered in some instances before or after culture through a Berkefeld $\mathrm{N}$ or $\mathrm{V}$ or a Massen filter, no observations are recorded on the pressure under which filtration took place nor the length of time which this operation took-indeed, owing to the exigencies of active service, observations on the pressure appear to have been impossible. It is, moreover, not stated what tests of individual filters were made to ensure that all bacteria of ordinary dimensions were held back; although some attempts to measure the particles which passed through are mentioned.

2. Cultivation. - The culture medium described by Captain Wilson is a modification of that used by Noguchi for the cultivation of spirochaetes and appears to have been identical for all the thirteen diseases investigated, though at times ascitic fluid was used instead of serum.

As bas been pointed out above, the demonstration of successful cultures depends on (a) the macroscopical appearances of the culture tubes or flasks, and (b) microscopical examination of the cultures.

Through the courtesy of Captain Wilson the writer has been able to examine stained films from his cultures, and also some material from his culture tubes with which he has made subcultures and films. Captain Wilson has also spent a considerable time examining some of the writer's cultures and films made from them and in pointing out the objects in films which he regards as the micro-organisms of trench fever and influenza.

The Macroscopical Examination of Cultures.

The macroscopical changes described by Wilson as seen in cultures consist of turbidity of the culture media, especially of the serum agar in the immediate vicinity of the rabibit kidney, and the formation of powdery or coherent material on the surface of the serum agar and later turbidity in the liquid medium above the agar.

It is claimed that the degree of the turbidity and the date of its appearance, together with the colour, amount, cohesion, and adhesion to the agar of these deposits, enable the observers to distinguish the viruses of several different diseases from each other, and also from the appearances seen in the control tubes containing all the same ingredients except the inoculum of virus.

It is, however, admitted that turbidity in the serum agar and a slight deposit on its surface do occur in the control tubes, but they are said to appear later and to be much less in degree than in tubes with growth of the virus. The changes in the control tubes, as has been pointed out to me by Lieut.-Colonel C. J. Martin, are apparently due in whole or in part to the autolysis of the kidney and the precipitate of denaturated serum-protein resulting from the consequent change in reaction.

* I am kindly permitted by Lieut.-Colonel C. J. Martin to sta te that he found the acid produced in ten days at $37^{\circ}$ C. in a control (sterile) Noguchi tube due to autolysis of a piece of kidney about $0.3 \mathrm{c.cm}$. in volume in $10 \mathrm{c.cm}$. of serum broth, equivalent to 0.3 to $0.4 \mathrm{c.cm}$. N/10
aqid per $10 \mathrm{e.cm}$. of broth, exclusive of $\mathrm{CO}_{2}$.
Microscopic Examination of Cultures.

As regards proof of culture, the most important and the most difficult part of the research consists in the recognition of the micro-organisms in the deposit removed from culture tubes and stain as as dry films and their differentiation from the appearances seen in similar films made from control tubes.

In order to establish the presence of one of the species of very small micro-organisms described by Bradford, Bashford and Wilson, satisfactorily in a film it must be distinguished not only from stained granules of protein, altered blood and kidney tissue, and from débris of cells which may be present in the serum or ascitic fluid, but also from other similar minute micro.organisms, of pathological importance or otherwise, which may be present in the inoculum or rabbit kidney, and especially from any of the other twelve viruses with which Bradford, Bashford and Wilson have worked. It is claimed by them that this differentiation can be made with so great accuracy that the tubes infected with these different kinds of virus can be used as controls against each other.

Besides these sources of fallacy the possibility of the presence of extraneous bacteria of ordinary dimensions, due to lapses in technique or infection of the rabbit kidney, etc., must be reckoned with.

Films from both Captain Wilsun's and the present writer's culture tubes show variously shaped and stained bodies which have been pointed out by Captain Wilson as representing the different filtrable viruses.

As far as the writer's observations go these bodies appear to belong to two different categories:

1. Bacteria which are only partially stained' owing to the age of the culture, the irregular action of the stain, or subsequent differentiation by washing.

2. Granules of precipitated protein and perhaps other unorganized granules closely resembling them. These granules vary very much in size, shape, and staining, but are frequently round or diplococcal in form or resemble very small bipolar staining bacteria. They are chiefly distinguished by their minute size, often about 0.3 to 0.2 micron or less, and their feeble staining properties (pink or lilac by Giemsa), and, as a rule, ill-defined outline.

These forms, both bacteria and precipitated granules, were found in some both of the inoculated and of the uninoculated control tubes.

\section{Trench Fever Films.}

1. The writer has had the opportunity of examining three films made by Captain Wilson, and dated September and November, 1918, from cultures of trench fever virus, the original source of the inoculum being different in each, case-two from patients' blood and one from infected louse excreta. The films were stained by methylene blue. The bodies seen in each film were very definite and fairly similar in the three cases. Groups or clumps were seen in very many fields, and were chiefly composed of very strall rounded bodies (about 0.5 micron in diameter), sometimes arranged in rows or pairs, and lying in a less well stained matrix. These appeared to resemble small diptheroid bacilli, so stained as only to show the polar granules. On carefully examining two of the films, in some places similar sized groups of organisms were found with a similar arrangement of granules, but here the staining was deeper and the granules were clearly seen to be contained in long and curved or short bacilli, resembling diphtheroids and arranged in clumps. Further in support of this view is the fact that films made from some of the writer's control tubes, which contained a very moderate amount of deposit, showed clumps of small diphtheroid bacilli which when deeply stained by carbol-methylene blue or carbol-thionin, and differentiated with alcohol, gave a very similar though not quite identical picture. The slight dissimilarity in the two cases is readily accounted for, since it is very probable that the diphtheroid bacilli in the two instances were not the same species. Subculture of these contaminated control tubes gave many small colonies of a diphtheroid bacillus.

2. Other freshly made films from Noguchi tubes inocu. lated by Captain Wilson or the writer with trench fever virus in blood or excreta showed very much less distinct forms; the granules were smaller and did not appear in rows, they were less well defined, and stained less deeply. These films also, in the opinion of Captain Wilson, con tained forms of the trench fever. micro-organism, but the 
present writor was unable to distinguish any appearances not found in control tubes. The granules in these films did not at all resemble, in his opinion, the organisms seen in Captain Wilson's other trench fever films and described in the last paragraph. These tubes gavt ao growth on subculture to agar and broth.

3. On June $23 r d, 1919$, a culture tube which had been inoculated by Captain Wilson some days before showed, in his opinion, macroscopically and microscopically, appear. ances characteristic of a trench fever culture. When a film was stained by carbol-methylene blue, large clumps containing blue dots were to be seen. A film stained by Gram's method and fuchsin showed only large Gram. positive staphylococci in clumps and masses, and these were seen in large numbers; no other forms resembling micro-organisms could be recognized by the writer in three films from this tube. Subcultures to an agar slope and broth gave a profuse growth of Staphylococcus aureus.

\section{Influenza.}

1. One sample of influenza sputum filtered and inoculated by the writer into Noguchi culture tubes gave no macroscopic or microscopic appearances which could be distinguished by the writer from those seen in control tubes. The films were stained by Giemsa.

2. On June 17th, 1919, Captain Wilson gave the writer some turbid blood-stained liquid, part of a culture which he had inoculated with the glycerinated blood of an influenza patient. He stated that this liquid contained abundant influenza micro-organisms. Films were prepared at once, and also subcultures were made on an agar. slope and in broth. The films stained by carbol-methylene blue and by Gram showed very large numbers of a large Grampositive coccus and no other organism. In a film stained by Captain Wilson with carbol-thionin and shown to the writer were seen large numbers of round organisms in groups which appeared to the writer to be the same coccus stained chiefly in the centre and under a lower magnification. This Captain Wilson regarded as the micro-organism of influenza. A staphylococcus grew readily in subculture on an agar slope and in broth.

In this communication no attempt has been made to criticize the work of Bradford, Bashford and Wilson on the experimental inoculation of cultures of these viruses into animals, but if the cultures used were contaminated with bacteria to the same extent as those from which films have been shown to the writer, then bacterial infection may be the explanation of certain of the symptoms and pathological changes produced.

\section{Conclusions.}

1. I have been quite unable to distinguish macroscopically or microscopically between tubes inoculated with trench fever or influenza virus (as far as the latter has been attempted) and control tubes at any period between their first inoculation and three weeks later, or over a longer period.

2. The culture tubes showing a considerable amount of deposit or turbidity of the serum broth have, when examined, always proved to be contaminated by bacteria as shown by subcultare and microscopical examination.

3. Two tubes selected by Captain Wilson from his own cultures after macroscopical and microscopical examination as good examples of growth of $(a)$ trench fever and (b) influenza virus proved to be grossly contaminated by large staphylococci and appeared to the writer to contain no other organisms.

4. Of three films shown as typical of the trench fever virus from different cases of trench fever and showing organisms of similar morphology, two appeared to be undoubtedly films of a diphtheroid bacillus irregularly stained, the third film also contained diphtheroid bacilli and in a ldition large numbers of a small bacillus of different appearance.

5. Other tubes regarded by Captain Wilson after macroscopical and microscopical examination as examples of cultares of trench fever which did not contain ordinary bacteria showed in the opinion of the writer only appear. ances which were also found in control tubes.

6. Thie forms claimed by Bradford, Bashford and Vilson as the micro-organisms of trench fever and influenza appear to the writer to be of two kinds: (a) Bacteria of the size of a staphylococcus or a diphtheroid bacillus, but only partially stained (polar or central staining).

(b) Smaller or larger granules of precipitated protein which stain much more feebly than $(a)$ and are also found in control tubes. Some of Captain Wilson's films appear to contain both and some only the latter forms.

In the opinion of the writer Captain Wilson has been misled by the appearances in films of bacteria feebly stained with methylene blue, in which only partial-for example, polar-staining is seen, and in the case of cultures from which bacteria have been absent he has been deceived by the diplococcus-like or dumb-bell shaped forms often seen in protein precipitates, and has regarded these granules as organisms.

That Bradford, Bashford and Wilson should have been so misled in their researches appears to be due to the following causes :

1. The conditions under which they worked-in isolation from other bacteriologists-conditions which wou'd scarcely have obtained in times, of peace.

2. A tendency to place undue reliance on the efficacy of filters and glycerin for removing or killing bacteria.

3. A misconception as to the size of the bodies seen in their films.

4. Inadequate staining.

5. Insufficent use of subculture on to ordinary media as a test for bacterial contamination.

In conclusion, I must express my appreciation of the readiness with which Captain Wilson has unreservedly placed certain of his films and cultures at my disposal, and my regret that $I$ am unable to accept his conclusions.

1 Bradford, Beshford and RFFerences.

1 Bradford, Bashford and Wilson: Quart. Journ. of Med.. 1918-19, 7ol. xii, p. 88. ${ }^{2}$ Bradford, Bashford and Wilson: Lancet, February 1st. 1919, p. 169. ${ }^{3}$ Bradford, Bashford, Wilson and Clayton: Quart. Journ, of Med., 1919, vol. xii, p. 259. "Sir John Rose Bradfor(3: Blitish MEDICAL Jo ORNAL, May $17 \mathrm{th}, 1919$, p. 599. ${ }^{6}$ E. F. Bashford p. 602. 7 American Red cross 6 J. A. Wilson: Ibid., May 17th. 19i9, Fever. Report of, Oxford University Press, 1918, p. 29-30. 8 H. Tönfer: Muench. med. Woch.1916, No.42, p. 1495,9 918 , p. 29-30. 8 H. Töpfer : Ibid., 1917, p. 1422. 10 Arkwright, Bacot and Duncan: Journ of Hugiere. 1919. vol. xviii, p. 76 . 11 H. Selter : Deut. med. Woch., i918, p. 932 . 12 Nicolle and Lebailly: Compt. rend. Acad. des Sciences, 1918, vol. clxvii, p. 607 . 13 Gibson, Bowman and Connor: Beriences, 1918 , JouRnAL, December 14th, 1918, p. 645. 14 Gibson, Bowman and Connor: Ibid.. Márch 22nd, 1919, p. 331 . 15 F. B. Bowman: Meeting of the British Medical Association. April, 1919. ${ }_{16}$ v. Angerer : Muench. med. Wuch.. 1918, p. 1280.17 Binder and Prell: Ibid.. 1918, pn. 1397 and 1456. 18 Flexner and Noguchi : Journ. of Exper. Med., 1913, vol. xviii, p. 461 . 19 George B. Foster, jun.: Journ. of Infectious Diseases, 1917, vol. xxi, p. 431. 20 H. Noguchi : Journ. of Exper. Med..

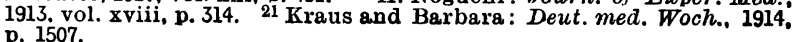

\section{NOTES ON DR. ARKWRIGHT'S ARTICLE.}

\section{By Sir John Rose Bradford.}

In view of the discrepancy in the results obtained by Dr. Arkwright and Captain Wilson respectively, it may be well for me to add a short statement with reference to Captain Wilson's work.

In the initial work on polyneuritis described in the Quarterly Journal of Medicine, Gram's method of staining was used as a routine, and it was also so used in the earlier work on certain other diseases, such as trench fever and influenza. It was subsequently discarded owing to the tendency to the deposit of stain with this method, and the non-use of this control has doubtless contributed in some instances to the failure to recognize the presence of contamination in certain cultures. The contaminations pre. sent in these contaminated cultures are to some extent peculiar, in that, as stated by Captain Wilson in his writings, full controls were always made both of the media used and of the inoculum. The methods of control employed were: first, the rabbit kidney and the inoculum were cultured by the ordinary bacteriological methods in common use; and, secondly, Noguchi control tubes were always put up, some with the inoculum but minus the kidney fragment, and others with the kidney fragment but without the inoculum.

All Noguchi tubes were rejected when, as sometimes happened, growth took place in any of such controls. It would seem, however, that some contaminations only grow in Noguchi culture tubes when both the inoculum and the kidney fragment are present. 